\title{
The Performance Evaluation System in Pakistan's Civil Service
}

TANWIR, Maryam | CHAUDHRY, Azam

\section{Abstract}

W hile achieving economic growth and development are dependent on the performance of the bureaucracy, there is a growing inability in Pakistan to objectively evaluate this performance. In this article, we examine performance evaluations systems that can be applied to developing country bureaucracies and find that the best system in the Pakistani context is the SMART performance evaluation system. We then analyze the present Pakistani system and compare it to an example of a SMART system and find that the disconnect between the actual performance of the civil service and the measurement of this performance by the performance evaluation report (PER) in
Pakistan, has discouraged optimal performance. The article also looks at the perceptions of senior civil servants themselves on what they perceive as the shortcomings of the performance evaluation management system in Pakistan as well as their opinions on a potential SMART performance evaluations system. The article recommends an immediate re-evaluation of the present performance management where the reevaluation initiatives must be tempered with the realization that the present system has been established not to optimize bureaucratic performance but rather to sustain the present system of patronage and power.

Keywords: Incentive, political capture, merit, service delivery, performance evaluation, civil service, perceptions, Pakistan 


\section{Introduction}

The bureaucrat is instrumental in the successful implementation of government policy and in making development a reality (Reynolds, 1983). The ability of the bureaucrat to transform the tenets of policy into the reality of development is dependent on the capability and capacity of the bureaucracy as an organization to ensure development. (Cheema and Sayeed, (2006); Kaufmann, Kraay, \& Zoido-Lobaton (2000); Evans \& Rauch 1999, (2000); World Bank, (1997).

The association between successful delivery and bureaucratic performance is difficult to identify and has led to an increasing interest in establishing the relationship between bureaucratic performance and development outcomes.

In the case of Pakistan, measures to augment the bureaucratic performance entail civil service reforms over the past decades. The reform has led to a system in which performance is supposed to be evaluated but these reforms have had little impact on actual performance. (Hussain, 2007; Tanwir 2010). The reason for this can be two-fold: Either the reformers may have implemented the wrong types of reforms or the civil servants may be resistant to reform since they feel that the present system is optimal for themselves and have created roadblocks for its implementation. We argue that the one of the possible reasons for this lack of impact might be because the Pakistani civil service reformers have failed to fully understand the various performance evaluation systems, which in turn means that the system that has been implemented is the wrong one for Pakistan. We also find that the majority of Pakistani bureaucrats recognize that the present system is flawed and would be willing to accept a revised system that accurately measures and rewards performance. In this article we look at the various models of performance management systems and narrow down the performance evaluation system that best fits the Pakistani context. After this we compare the present Pakistani performance management to an example of the optimal system we have chosen and find that the Pakistani system falls far short. Finally, we take our analysis one step forward and look at what are the perceptions of the Pakistani bureaucrats regarding a revised performance management system and find that there is an overwhelming recognition amongst the bureaucrats that the present system is flawed and that they are willing to accept a new system. 
The setup of the article is as follows: Section I one provides the introduction. In Section 2 we explain the link between civil service performance and economic development. In Section 3 we present the various types of performance management systems and see how the SMART system is the best fit for the Pakistani civil service. In Section 4 we see how the present Pakistani performance management system compares to the SMART system. In Section 5 we look at how current bureaucrats view the present Pakistani performance management system as well as how they feel about the elements of a new performance evaluation system based on the SMART system. In Section six 6 we present conclusions.

\section{The link between Civil Service Performance and Development}

The main reason for civil service reform is that policy makers realize that there is a direct relationship between the performance of the bureaucrats and public service provision, leading to the overall development objectives of society. In this section we look at the evidence on the link between civil service performance and development.

There are now both case studies and cross-country empirical analyses that affirm that bureaucratic performance is essential for development (Kaufmann et al, 2000; Evans \& Rauch, 1999, 2000; World Bank, 1997, Kohli, 2006). The primary instrument of the developmental states remains a competent and a professional bureaucracy (Evans, 1995). The miracle of the East Asian developmental state has largely been attributed to the role of the professional and autonomous bureaucracy, which closely approximate the Weberian mode ${ }^{21}$ (Chang, 2002).

As the literature highlights an efficient and well performing bureaucracy is a catalyst for the modern developmental state, it also informs on the costs of inefficient performance of the bureaucrat. The inefficiency and incompetency of the bureaucrat have grave consequences for the nation state. Huber and McCarty (2004) inform that when bureaucratic capacity is low, successful policy making remains hostage, as

\footnotetext{
${ }^{21}$ Having inherited the colonial British Weberian model at its birth in 1947 (Briabanti, 1966) provided the starting point for establishing the characteristics of bureaucratic performance in Pakistan
} 
politicians ${ }^{22}$ in such polities get trapped in a situation whereby they have little incentive to undertake reforms of either the bureaucracy or other institutions which are quintessential for efficacious policymaking.

Underlining the significance of the efficiently performing bureaucrat and the close correlation to positive development outcomes, governments and practitioners have turned their attention towards augmenting the capacity of the bureaucrat (Matheson, $A$. et al. (2007); Pollitt \& Bouckaert, (2000) .This is more important than ever before, as with the 21 st century, the forces of globalization, and increasing volatility and irregularity within the social and economic environment, has called for the civil service, particularly the senior civil service to realign and reinvent itself to cope with the evolving strategic challenges. In this process of reinvention and modernization of the senior bureaucracy, modernizing the performance management and performance evaluation of the civil servants has emerged as a key concern in public administration (IPPR 2013: 13-14)

Thus the literature explicates how a well-functioning bureaucracy is a critical component for development. In the next section we explain performance management and introduce the performance evaluation report as a key criterion, in the context of the civil service and discuss various models that are relevant in the development country context.

\section{Performance Management Systems in the Context of the Pakistani Bureaucracy}

In this section we look at what performance management systems are and what they mean in the context of developing country bureaucracies. We then look at various models of civil service performance management systems and find the one that best fits the Pakistani context.

Performance is now seen as being fundamental to the modern state (Matheson, A. et al. (2007), and the modern state has primacy only to the extent it performs and performance management and evaluation remains the primary means by which public service goals are linked to individual target-setting, appraisal and development. It provides a strategy for delivering a higher quality (public) service and for increasing

\footnotetext{
${ }^{22}$ The Pakistani bureaucracy has been charged with increased politicization (Tanwir and fennel, 2010)) as there is a rise of the transfers of bureaucrats between official posts that appear to be related to political machinations.
} 
efficiency by enhancing accountability and individual motivation, and improving communication to assist organizational change. Pollitt and Bouckaert (2004) offer an integrated analysis of the wave of management reforms which have swept through several countries in the last decades. Their research suggests that optimal performance management and accurate measurement is of crucial significance to ensure successful development outcomes.

The origin of the literature performance management lies in the financial management and economics literature in which firms are judged by their shareholders based on measures of profitability (see Kaplan and Norton, 1996 and Morisawa, 2002)or organizations are judged by their stakeholders on measureable criteria such as increased effort and productivity (See Otley, 1999). Performance management has been defined and interpreted in different contexts and organizations. It can be understood as:

The periodic measurement of progress toward explicit short and long run objectives and the reporting of the results to decision makers in an attempt to improve program performance (Poister, 1983:3).

In terms of performance management what comes to the forefront is the term Performance Measurement, which is a key element in augmenting performance.

Performance measurement is intended to produce objective, relevant information on program or organizational performance that can be used to strengthen management and inform decision making, achieve results and improve overall performance, and increase accountability (Positer, 2003:4)

Though the literature on performance measurement systems is diverse in nature, the three major models of performance measurement that have emerged are (1) the balanced scorecard model, (2) the performance pyramid (or SMART system) and (3) the performance prism. The balanced scorecard was developed by Norton and Kaplan (1990) and established the link between financial/operational measures with outcomes measures such as customer satisfaction, productivity, value, etc. The performance pyramid or SMART system of Cross and Lynch (1992) was different from the balanced scorecard model in that it recognized that organizations were hierarchal structures and thus the SMART model provided a link between performance measures at each of these 
levels aimed at achieving an overall organizational objective which was the summit of a 'pyramid'. The performance prism model was developed by Neely et al (2001) and goes beyond the ideas of the other models by incorporating the idea of what stakeholders actually want and looking at performance management through this lens.

In the context of developing country bureaucracies, performance management and evaluation systems are those systems that improve service quality in the bureaucracy as well as lower costs and increase accountability to stakeholders. As Garvin (1993) has aptly informed, "if you cannot measure it, you cannot manage it." Accurate performance measurement tools would warrant if the work rendered is satisfactory and adequate or indicate warning regarding dismal performance of the civil servants. Accurate and objective performance measurement would lend clarity when examining the cause of the success or failure of development programs performance management can also provide signals to what may be the problem, whether it is the performance of the bureaucrats or other extraneous factors which need consideration.

Positer (2002) informs that accurate Performance measures can provide managers and policymakers with valid, reliable, and timely information on how well or how poorly a given program is performing, however he does stress that ultimately it will be the responsibility of the managers and policymakers to respond effectively to improve performance (Positer, 2002:272)

As a natural consequence of an accurate bureaucratic performance evaluation system, there would be weightage on good performance and subsequently good performance would be recognized and rewarded by promotion to the next senior grade. Furthermore, seniority would imply higher quality of management, where the senior is superior in experience and skills to the junior colleague. A good performance evaluation system would provide incentive for efficient performance of the civil servant and provide an accurate indicator to evaluate that performance. It would also reward good performance and discourage inefficient performance. It would also imply that the senior officers are more competent as their promotions were based on efficient performance. It would also imply that the officers occupying important posts have reached there by seniority and merit, and are qualified for the job and will work efficiently and promote development initiatives. The following figure illustrates the argument: 


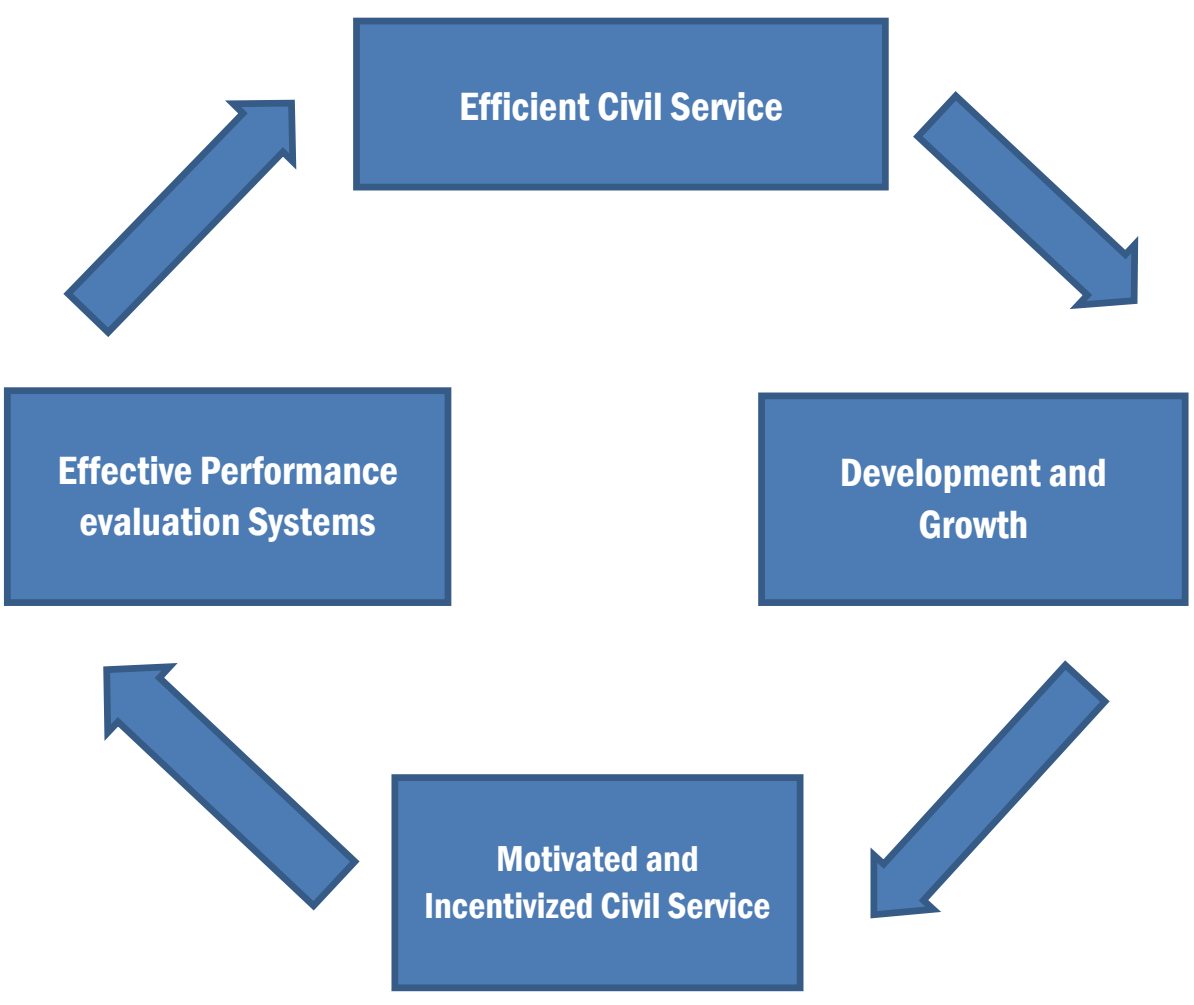

Source: Authors own

But the question that arises after this discussion is which model of performance evaluation fits Pakistan the best? The Pakistani bureaucracy, like many developing country bureaucracies is based on a system where compensation is purely based on seniority (which is usually more linked to years of experience rather than performance) but positions or 'postings' are supposed to be based on performance. This means that in the Pakistani context an effective performance evaluation system that objectively and accurately assesses the performance of its officers and on the basis of the assessment of performance offers recommendations for future transfers and promotions is a very 
important tool in ensuring that the well performing, efficient officers are posted and promoted correctly, so as to better pursue developmental work.

In this context, the balanced scorecard approach does not fit the Pakistani system because it tries to link measures of performance with outcome measures such as development but it ignores the hierarchal structure that is inherent in the Pakistani bureaucracy. On the other hand even though the performance prism model takes into account the structure of the Pakistani bureaucracy, its emphasis on looking at performance through the lens of the stakeholder can be tricky in the Pakistani case: Is the principle stakeholder the political entities that decide on bureaucratic transfers, promotions or postings or is it the citizens of Pakistan that have little impact on the careers of bureaucrats? And if it is the latter, then how can bureaucrats be held accountable to these citizen stakeholders? So, the performance evaluation system that fits the Pakistani bureaucracy the best is the performance pyramid or SMART system which takes into account the hierarchal nature of the Pakistani bureaucracy and links measurable performance measures with measurable outcome measures in terms of an overall objective which in the Pakistani context is economic development.

\section{Comparing the Pakistani performance evaluation system with the SMART System}

In this section we describe the current Pakistani performance evaluation system for civil servants as well as comparing it to an example of the SMART system of performance management.

Examining the performance management system, one finds that as opposed to international best practices it only contains one performance evaluation report (PER). (The performance management system and the performance management report are quintessentially the same and only primary criteria of managing and evaluating bureaucratic performance $)^{23}$.

\footnotetext{
${ }^{23}$ Unlike the UK Performance management system, where the PER is only one part of the whole management system, there exists only one document the Performance evaluation report that determines the career trajectory of the civil servant. As the next section will elaborate there are no prior objectives and which are first discussed and no specific targets that are agreed by the line manager and officer and then reviewed bi annually, and then assessed annually, where the officer himself comments on the attainment (or the lack of) targets and objectives. But the PER is just simply filled up the line manager, the next in command.
} 
The PER (previously termed as the annual confidential report (ACR) is filled out by the senior/boss of the officer being assessed and is the most important criteria for assessing whether the officer is worthy of being promoted to a higher grade or not. This document according to Weber (1968) should be based on merit and performance. Evans and Rauch (1997) similarly talk about promotion based on performance as a key Weberian criterion, that would ensure predictable long term careers, and it would imply a system that rewards performance and discourages incompetence. According to Weberian Tradition the PER should be an objective and fair assessment of the officer concerned, and it should recommend a promotion to a higher grade if the performance warrants it. According to Weber (1968) promotion is contingent on the on judgment of superiors. If promotion is lacking, or further capacity building of the officer is required then it should report these facts accurately also ${ }^{24}$.

The World Bank report (1998) also acknowledges the failings of the ACR in assessing actual performance, and its lack of provision of an objective basis for determining promotions. The inadequacy of the ACR in gauging performance is confirmed by Cheema and Sayeed (2006) who report that the ACR emphasizes the personal qualities of the officer rather than to setting objective and measurable targets against which performance can be assessed. Tanwir (2010) informs on the lack of correlation between the PER and the performance of the civil servant. Research conducted by Pakistan Institute of development economics (PIDE, 2006), informs that the promotions are not based on merit. But it appears that the rationale for these decisions is a combination of political pressure and rent sharing.

The report informs that the bureaucrats insist on clear job description as being mandatory for effective management and performance, which is missing in the Pakistani case. And without a clear job description, the performance cannot be effectively assessed and hence merit and reward system cannot be established. However The World Bank (1998) acknowledges that the PER would be of limited utility in developing a performance oriented culture even if used boldly. Because these systems give greater

\footnotetext{
${ }^{24}$ For this section it is important to highlight that a Favorable performance evaluation reports is conducive for career progression in the bureaucracy. It is the document that is necessary to finalize the promotion of the officer. A very important document that is quintessential for an upward career trajectory of the civil servant. It gives the officer the incentive to perform efficiently and determines his success or lack off in his career trajectory.
} 
emphasis to personal qualities than to setting objectives and measurable targets against which performance can be objectively assessed, consequently many commonwealth countries are now moving to such objective driven systems and find that focusing on outcomes enhances the objectivity of reports.

As discussed above, the present Pakistani performance evaluation system is fundamentally flawed. Another way of analyzing the system would be to compare it to the British system which is an example of the SMART system that we feel would be the optimal performance management system in the Pakistani context. We specifically choose the British PER for two reasons.

Firstly, Both India and Pakistan inherited the colonial British Weberian model at its birth in 1947 (Briabanti, 1966), which provided the starting point for establishing the characteristics of bureaucratic performance in Pakistan. Not only have we inherited the British civil service as our colonial legacy but the British civil services has recently adapted some of the best international practices prevalent in performance evaluation systems all over the world. A key action of the latest civil service reform plan calls for a rigorous performance management and appraisal system, where performance will be further strengthened by standardizing competency frameworks across government and implementing a tougher appraisal system. It mandates that Good performance will be rewarded and efforts will be made to tackle poor performance tackled (cabinet office, 2013/14).

The UK performance management and appraisal system does not only rest on a PER but has a full umbrella system for appraisal. The UK system mandates that each senior civil servant will first develop an agreement with his/her line manager and this will include a mutual agreement consisting of targets and objectives to be achieved. This will encompass performance planning at the beginning of the annual business cycle to provide individuals with direction and stretching objectives; performance review throughout the business cycle to ensure objectives remain relevant and good progress is being made, and formal performance assessment at both mid and end-year points. The performance evaluation report specifies that Objectives which are set and agreed on, must be must be SMART (Specific; Measurable; Achievable; Relevant; Timed). And for each objective job holders should record the main actions to be carried out with deadlines wherever possible, and the measures or targets which will be used to assess whether the objective has been successfully delivered. And once finalized and agreed, 
the objective form must be cascaded by the job holder to at least the management level below $^{25}$. In the UK, under the performance management system, the agreement with the line manager is for a period of 12 months.

An important point highlighted in the UK performance evaluation system is that the Performance indicates both the completion of objectives and the manner in which they were completed or achieved. This would significantly impact the quality of work rendered, and assessed. The HR practitioners guide (2013) stipulates that the performance of job holders must be assessed by taking account of both 'what' and 'how' the targets have been achieved.

To evaluate the performance of the senior civil servant, the same two parties are involved who initially drew up the agreement; the line manager and the senior civil servant. There are two evaluations: A mid-year review and an end year review. A midyear review gives the opportunity to both parties to revisit the agreement and targets and alter if the need arises. And the end year review the senior civil servant himself writes a report on his work emphasizing on achievement or missed targets which were initially agreed. The senior or line manager will then recommend a promotion or bonus, increased autonomy, all contingent on his view of the performance of the civil servant. There is also a possibility of under achievement of targets and poor performance will translate into the development of a performance improvement plan before any formal dismissal is considered. Furthermore, if the underperformance continues the civil servant will be eventually dismissed from service (Horton, 2006).

On introspection it appears that the Pakistani and British PER diverge across many different dimensions. The comparison between the two reports on different dimensions informs that, the while British PER is very explicit in stating the budgetary allocations and manpower responsibilities, and the Pakistani PER is much less categorical and states the allocations and responsibilities in a more abstruse manner.

Although both reports ask for targets and statistical evidence of achieving targets but the British PER also asks for deliverables in the report, which is lacking in the Pakistani PER. Furthermore another significant difference between the two reports is the number

\footnotetext{
${ }^{25}$ The intention is to ensure clear accountabilities about who is responsible for what, and to enable job holders to go on to set objectives and work plans for their teams. In addition, it is envisaged that cascading objectives will increase the quality of objective setting, and will facilitate effective 360 degree feedback, by staff being clear about the objectives the SCS are working to deliver.
} 
of assessments carried out. British PER has a mid-year and an end year assessment while the Pakistani PER is assessed one a year. The British PER performance assessment is based on performance against targets and behavior. While the Pakistani PER inquires more in regard to general behavior (honesty, communication skills, strengths, weaknesses). The British PER objective performance criteria ask for the clear list of each objective from earlier in the form and inquires on the manner through which the civil servant has achieved each objective. The Pakistani PER does not inquire in this regard and is far more subjective. Gunnigle et al (2006, p.167,) give the difference between analytical or non-analytical assessment criteria, and these differences are evident in the comparison between Pakistani and British PER report. The British (analytical) assessment criteria involve jobs being broken down into a number of critical factors that are then analyzed and compared using a quantitative measure. Pakistani (Non analytical) job evaluation represents more of a general overview of the job as indicated by the role profile, without consideration of the constituent parts. Analytical job evaluation is generally seen as more rigorous and objective. Although both Pakistani and British PER both ask for subjective assessments. But the British PER also asks for objective measurements of how the civil servant achieved each target on a scale of $1-3$ :

1) Met expectations

2) Not met expectations

3) Exceeded expectations).

The Pakistani PER does not; and last but not any less importantly the British PER has punitive sanctions for officers who have not performed optimally; unfortunately this is not the case in the Pakistani PER.

Some of the key differences between the SMART British performance evaluation system and the Pakistani performance evaluation system are illustrated in table 1 below: 
The Performance Evaluation Systems in Pakistan's Civil Service 93

Table 1: Comparison of the British SMART System and Pakistani Performance Evaluations Reports (PER)

\begin{tabular}{|l|l|l|}
\hline Criteria for comparison & UK PER & Pak PER \\
\hline Time frame for discussing targets & Yes & No \\
\hline Time frame for discussing performance evaluation & Yes & Yes \\
\hline Establishing Analytical targets & Yes & No \\
\hline Evaluation of Bureaucratic Competency & No & Yes \\
\hline Evaluation of Bureaucrat's strengths and weakness & No & Yes \\
\hline Evaluation of Bureaucrat's Honesty & No & Yes \\
\hline Provision for punitive measures & Yes & No \\
\hline
\end{tabular}

Source: Authors own

\section{Perceptions of Pakistani civil servants on the present Pakistani performance evaluation system and elements of a potential SMART system}

\section{Importance of determining perceptions of civil servants}

In the discussion above we have established three distinct points: First, civil service performance is critical for development and growth. Second, that civil service performance is linked to performance evaluation systems. And third, that the Pakistani civil service performance evaluation system strays significantly from the optimal system in the Pakistani context, which has translated into detrimental outcomes for the bureaucrat and the economy.

But in the Pakistani context there is still one unanswered question: Does this deviation from best practices in terms of the Pakistani performance evaluation system impact bureaucratic performance? This question is far from trivial since the argument can be made that the present performance evaluation system though far from the best practices case works in the Pakistani context which could be because the best practices 
simply does not work on Pakistan or alternately the Pakistani context is so different that the present system has been developed to optimize bureaucratic performance. If this is the case, one can argue that the Pakistani performance evaluation system works and in turn has a positive impact on development.

In order to determine the true efficacy of the Pakistan performance evaluation system, we conducted a unique survey of senior civil servants to determine what their perception of the present system is and whether the present system is optimal in terms of determining bureaucratic performance as well as motivating high levels of bureaucratic performance. We also asked them questions on the perceptions of senior bureaucrats regarding elements of a potential SMART system. This was important to judge their perceptions about the benefits of a new SMART system which also is indicative of how receptive they would be to the implementation of a new SMART system.

\section{The structure of the survey}

In order to determine the perceptions of senior Civil Servants in Punjab regarding the present performance evaluation system we developed and administered a detailed questionnaire for senior civil servants. The questionnaire was informed by the comparison and contrasts of the British ${ }^{26}$ and Pakistani performance evaluation system. More than 100 senior civil servants were surveyed to determine their perceptions regarding the efficacy of the present system as well as their recommendations for restructuring the present system. The survey was carried out in January 2014, at the National institute of public administration, Lahore. The civil servants were in training courses at the institute. What makes this survey unique is that it was conducted for civil servants from a variety of services, and not only by the District management group (DMG) as initially envisaged. The details of all the different service groups surveyed are given in the appendix.

\footnotetext{
${ }^{26}$ The reason for focusing on the British management system was twofold. a) The recent 2013 Performance management system (PMS) introduced in the cabinet office, has the potential of being one of the best globally, and contains best practices approved internationally b) Pakistan inherited the British bureaucracy as its colonial legacy, and has a similar Weberian structure.
} 
The questionnaire was divided into different sections which inquired on the strengths and weaknesses of the present performance evaluation system. It inquired on the nature of the targets set in the system and the links between efficiency of performance and postings, and link between performance, training and pay structures.

\section{Results from survey}

The survey looked at the three critical aspects of the link between bureaucratic performance in Pakistan and the Pakistani performance evaluation system. First, it looked at perceptions of bureaucrats regarding the system itself. Second, it looked at the link between civil service performance outcomes and the present civil service performance evaluation system. Third, it asked about possible changes to the present system of civil service performance evaluation.

Firstly we looked at the perceptions of bureaucrats regarding the present performance evaluation system. The reasons for looking at these perceptions was to determine whether the present system was supported by the civil servants since this impacts how civil servant behavior may be impacted by performance evaluations. The findings were significantly negative which supports the idea discussed above that the Pakistani performance evaluation system deviates significantly from best practices. Also this deviation may have a significant impact on bureaucratic performance. Some the key results of the first part of the survey were:

- $85 \%$ of the civil servants (CS) perceived the current performance evaluation report (PER) to be inaccurate in assessing their performance.

- $81 \%$ of the Cs perceived that the PER was not a motivator for their performance.

- $70 \%$ of CS confirmed that the current PER was highly susceptible to political manipulation.

- $70 \%$ of the CS though the PER was subjective and lacked tangible objective criteria.

- $\quad 99 \%$ of the CS confirmed that no targets were agreed between the officer and the senior manager for public service delivery. 
The results of this section of the survey suggest that even though accurate performance evaluation is quintessential for public service provision (and positive development outcomes) the present performance management system is inaccurate, highly susceptible to political interference and lacks tangible criteria for assessing performance which negatively affects the performer and the assessor. This in turn has a negative impact on development in Pakistan.

Next the survey looked at the link between bureaucratic outcomes and the present performance evaluation system. This was critical since it answers the question of whether the present system may be still motivating civil servants to perform even if it is far from optimal. What we find is that there is absolutely no link between actual bureaucratic performance and the present performance evaluation system which strongly suggests that the present system is failing to adequately measure civil service performance. Some of the key results of the survey are:

- $78 \%$ of the CS agreed that there was no link between efficient performance and the present performance evaluation system.

- $70 \%$ confirmed that there was no link between efficient performance and training opportunities.

- $84 \%$ confirmed that there was no link between efficient performance and better/plum postings.

- $\quad 70 \%$ of the CS said there was no link between efficient performance and pay.

These results suggest that the present performance evaluation system fails to be a motivator for efficient performance. This also implies that the bureaucrats in the most important positions are not the best qualified or even the best performers, which has a significantly negative impact on bureaucratic outcomes which in turn cause low development outcomes."

The final aspect we looked at was what civil servants thought about a new system based on the SMART model of performance evaluation. This is important since the argument can be made that even though the present system is inefficient in measuring bureaucratic performance, a better system will fare no better in motivating bureaucrats to perform better. Or in other words, even if the flawed system of performance evaluation was fixed, the civil servants would not perform any better. But based on our 
survey results we find the opposite: A significant number of civil servants wanted to reform the present performance evaluation system based on the principles of the SMART system and even though this may not be popular with politicians they want objective, quantifiable criteria that are not subject to political manipulation. Some of the key results of the survey were:

- $\quad 90 \%$ said that there should be quantifiable targets in the PER.

- $95 \%$ confirmed that there can be objective criteria in the PER which cannot be politically manipulated.

- $70 \%$ of CS confirmed that they don't think the politicians want an objective PER system.

- $75 \%$ of the CS want to have an objective PER which is not susceptible to political manipulation).

These results suggest that without quantifiable targets in the PER which are beyond political manipulation there can be no way forward for accurate assessment of bureaucrats which is critical because bureaucrats blame this failure for low bureaucratic performance and outcomes.

\section{Implications of results}

The results from the survey of senior Pakistani civil servants are not just interesting from the Pakistani perspective but rather have deeper implications for all developing countries. The reason is that in the developing country context it is believed that poor bureaucratic performance is the result of either lack of effort on the part of bureaucrats, corruption or ineptitude. No matter what the reason, it is well understood and well documented that low level of bureaucratic effort leads to poor bureaucratic performance which in turn leads to poor development outcomes. But our results show that one of the principle reasons for low effort by the Pakistani bureaucrats is that this is a reaction to the Pakistani performance evaluation system in place at present. This poor performance evaluation system is strongly susceptible to political interference and corruption which means that bureaucrats tend to politically align themselves with individuals and parties and concentrate their efforts on pleasing them as opposed to maximizing social and developmental outcomes. This means that the individual 
bureaucrats are completely rational in their decisions of how much work to do and what work to do which in turn determines their career trajectory in the present system. But in the end these perverse incentives lead to the bureaucrats and politicians colluding to maximize individual benefit at the expense of national benefit.

Another implication is that despite what politicians and political parties say, there is very little incentive for them to alter the system since they receive the maximum benefits from it. One the other hand the civil servants are overwhelmingly in favor of changing the present system into a system that reflects the SMART principles of performance evaluation. This has the potential to have a significant impact on bureaucratic performance and developmental outcomes. But like civil servants in most developing countries, they realize that this transformation is not something that the politicians truly want which means that developing countries like Pakistan may be caught in low civil service performance traps which result in weaker institutions as well as poorer developmental outcomes.

\section{Conclusions}

We have shown that the optimal performance evaluation system used to measure the performance of Pakistani bureaucrats is the SMART system which is not being implemented in the Pakistani case. In particular the present Pakistani system fails is establishing objective criteria for assessment as well as emphasizing aspects that are completely unrelated to bureaucratic performance. But even after this the argument can be made that the present system works well in the context of Pakistan and bureaucratic performance is maximized for positive development outcomes.

In order to test this idea we conducted a novel survey of senior civil servants which showed that there is a significant disconnect between the present performance evaluation system and the actual performance of civil servants. This in turn has led to significantly negative perceptions of the present performance evaluation system. But perhaps most importantly the survey shows that the majority of civil servants would like significant changes in the present performance management system to make it a more accurate representation of actual civil service performance outcomes.

The implications of this research is that there needs to be an immediate reevaluation of the present performance management systems of Pakistani bureaucrats which makes 
it an accurate and objective measure of bureaucratic performance which is not susceptible to political interference. But these recommendations must be tempered with the realization that the present system has been established not to optimize bureaucratic performance (or for that matter for furthering development outcomes) but rather to sustain the present system of patronage and power. So these performance evaluation system reforms have to be accompanied by an effort to convince the political elites that an independent and motivated bureaucracy will lead to more winners than losers. The first step in this process will be to conduct further research that proposes revisions to the present system and explain to all the stakeholders that switching to this new system will result in more winners than losers as well as better long term development outcomes.

\section{List of References}

- Armstrong and Baron (1998), Performance management, The new realities. Institute of personnel and development, London

- Briabanti, R (1966), Research on the bureaucracy of Pakistan, Duke University press, Durham.

- Cabinet Office (1999), Modernizing Government White Paper. London Stationery Office

- Cabinet Office (2004), A HR Practitioners Guide to Performance Management and Reward in the SCS. London Cabinet Office

- Cabinet office (2011), Performance management for the senior civil service 2011/2012. A guide for HR practitioners London Cabinet office

- Cabinet office, (2013) Performance Management arrangements for the Senior Civil Service 2013/14

- Chang, H (2002), Kicking Away the Ladder - Development Strategy in Historical Perspective, Anthem Press, London.

- Cheema and Sayeed (2006) Bureaucracy and Propoor Change (PIDE Working Paper No. 3) 
- Cross, K. F. and Lynch, R. L. (1992) "For good measure", CMA Magazine, Vol. 66, No. 3, pp.20-24.

- Drucker, P (1954) The Practice of Management (New York: Harper \& Brothers)

- Evans \& Rauch (1999) Bureaucracy and Growth: A cross-national analysis of the effects of Weberian state structures on Economic growth. American sociological Review; Oct (1999) 748-765

- Evans \& Rauch (2000), Bureaucratic structure and bureaucratic performance in less developed countries. Journal of Public economics, 75, Jan (2000)49-71

- Garvin, D (1993) "Building a learning organization" Harvard business review, 71, 4, 78-81

- Haque, Nadeem UI, and I. Khawaja (2007) Public Service through the Eyes of Civil Servants. (PIDE Series on Governance and Institutions). Islamabad: Pakistan Institute of Development Economics.

- Hayat, A (2004) Syndicate report, 'The Challenge of public service in Pakistan: Approaches to civil service 'Faculty Advisor: Mr. Akhtar Hayat, by Pakistan Administrative staff college, Lahore.(80TH NMC, Jan - May 2004)

- Hondeghem and Van Dorpe, (2012), Performance management systems for senior civil servants: how strong is the managerial public service bargain? International Review of Administrative Sciences 79(1) 9-2

- Horton, S (2006), General Trends and challenges regarding performance evaluation of staff: The UK experience. Portsmouth University United Kingdom Seminar on "Civil Service Performance Appraisal" Vilnius, 23-24 May 2006

- HR Practitioners' Guide (April 2013).London Cabinet office. http://www.civilservice.gov.uk/wp-content/uploads/2012/04/Performance-ManagementArrangements-for-SCS-2012-13-HR-Practitioners-Guide.pdf

- Huber and McCarty (2004). Bureaucratic Capacity, Delegation, and Political Reform. American Political Science Review, pp 481-494. doi:10.1017/S0003055404001297

- Humble, W (1972) Management by objectives. Objectives. Management Publications, 1972

- Hussain, I (2007), Reforming the Government in Pakistan: Rationale, Principles and Proposed Approach, the Lahore Journal of Economics Special Edition

- IPPR, (2013) accountability and responsiveness in the senior civil service: lessons from overseas, cabinet office, www.cabinetoffice.gov.uk 
- Kaplan, R. \& Norton, D. (1996), The Balanced Scorecard. Harvard Business Press.

- Kaufmann, Kraay, and Pablo Zoido-Lobatón (2000) "Governance Matters: From measurement to Action" Finance \& Development, June 2000, Volume 37, No.2

- Kennedy (1991), Charles H. "Bureaucracy in Pakistan" Oxford University Press, Karachi, 1987

- Ketelaar, A., N. Manning and E. Turkisch (2007), "Performance-based Arrangements for Senior Civil Servants OECD and other Country Experiences", OECD Working Papers on Public Governance, 2007/5, OECD Publishing. doi:10.1787/160726630750

- Kohli, A (2006) State-Directed Development: Political Power and Industrialization in the Global Periphery, Cambridge university press.

- Kopric, Ivan, (2010) Managing performance in the Western Balkans Civil service structures. UNDP

- Levinson H, (1976) Management by whose objectives? Harvard business review. Julyaugust

- Long, P (1986) performance appraisal revisited. London, institute of personnel management

- Matheson, A. et al. (2007), "Study on the Political Involvement in Senior Staffing and on the Delineation of Responsibilities Between Ministers and Senior Civil Servants", OECD Working Papers on Public Governance , 2007/6, OECD Publishing doi:10.1787/136274825752

- Morisawa, T, 2002, Building Performance Measurement Systems with the Balanced Scorecard Approach, Numera research Institute, NRI, Paper No.45

- Neely, A., Adams, C., and Crowe, P. (2001) "The performance prism in practice", Measuring Business Excellence, Vol. 5, No. 2, pp.6-12

- OECD (2007), Ageing and the Public Service: Human Resource Challenges. OECD Paris.

- Otley, D (1999).A Framework for Management Control Systems Research. Management Accounting Research, Vol 10, No 4, December 1999. Available at SSRN: http://ssrn.com/abstract $=185488$

- Parizek, Michal (2012) Performance appraisal in the Western Balkans: Overview and good practices from a capacity development perspective, UNDP 
- PIDE, (2006), Perception Survey of Civil Servants: A Preliminary Report, Pakistan Development Review, 2006, 45:4, 1199 -26

- Plachy R.J (1987) the point factor job evaluation system: a step by step guide. Compensation and benefits reviews. Sep -October.

- Poister, T, (2003) Measuring performance in public and nonprofit organizations, Published by Jossey-Bass A Wiley Imprint 989 Market Street, San Francisco, CA 94103-1741

- Poister, T. H. Performance Monitoring. Lexington, Mass.: Heath, 1983

- Pollitt and Bouckaert, (2000) Public Management Reform: A Comparative Analysis: A Comparative Analysis, Oxford University Press.

- Report of the National Commission for Government reforms on reforming the government in Pakistan Vol I (MAY 2008 ) National Commission for Government Reforms Prime Minister's Secretariat Government of Pakistan Islamabad. http://www.pc.gov.pk/wpcontent/uploads/2014/11/NCGR_Vol_I-1.pdf

- Reynolds, G (1983) "The spread of economic growth in the third world: 1850-1980", Journal of economic literature, vol 21, no.3 published by American economic association.

- Rice and Patrick (2008) "Index of the state weaknesses in the developing world" The Brookings institution.

- Ritzen, easterly \& Woolcock, (2000) "On "Good" Politicians and "Bad" Policies: Social Cohesion, Institutions, and Growth" The World Bank

- Schick, Allen (2005), "The Performing State: Reflection on an Idea Whose Time Has Come but Whose has not. Brookings institute Organization for Economic Co-operation and Development

- Tanwir and Fennel, (2010) Political Neutrality and the Pakistani Bureaucracy: a mutually exclusive phenomenon?' PDR Vol. 49, No.3, autumn 2010. http://pide.org.pk/pdr/index.php/pdr/article/view/2713/2677

- Tanwir, M (2010) Bureaucratic perception of merit, gender and politics (unpublished PhD Dissertation) University of Cambridge

- Weber, M (1968) Economy and society, an outline of interpretive sociology, edited by Roth, $\mathrm{G}$ and Wittich, Bedminster press, New York

- Wilson, R. (1999), Reform of the Civil Service. London Cabinet Office 
- World Bank (1997) World Development Report, The State in a Changing World Oxford University Press.

\section{Appendix_Breakdown of Surveys Conducted by Department}

\begin{tabular}{|l|l|l|}
\hline & Number & Percentage \\
\hline Total Bureaucrats & $\mathbf{1 0 2}$ & $\mathbf{1 0 0}$ \\
\hline Civil Service & 4 & 3.92 \\
\hline No Information on Service & 15 & 14.71 \\
\hline Pakistan Administrative Service (PAS) & 11 & 10.78 \\
\hline Pakistan Railways (RLY Group) & 6 & 5.88 \\
\hline Pakistan Audit and Accounts Service (PA\&AS) & 10 & 9.80 \\
\hline Secretariat Group (SECTT Group) & 10 & 9.80 \\
\hline Inland Revenue Service (IRS) & 11 & 10.78 \\
\hline Police Service of Pakistan (PSP) & 8 & 7.84 \\
\hline Customs Group & 3 & 2.94 \\
\hline Foreign service of Pakistan & 4 & 3.92 \\
\hline Other & 19 & 0.19 \\
\hline
\end{tabular}

\section{Source: Authors own}

\section{AUTHORS' CONTACT:}

TANWIR, Maryam

Centre of Development Studies University of Cambridge Email:mt383@cam.ac.uk

\section{CHAUDHRY, Azam}

Professor, Dept of Economics, Lahore School of Economics

Email: Azam@Lahoreschool.edu.pk 